\title{
Engineering lacZ Reporter Gene into an ephA8 Bacterial Artificial Chromosome Using a Highly Efficient Bacterial Recombination System
}

\author{
Yujin Kim, Eunsook Song, Soonyoung Choi and Soochul Park* \\ Department of Biological Science, Sookmyung Women's University, Chungpa-Dong 2-Ka, Yongsan-Ku, Seoul 140-742, Korea
}

Received 6 February 2007, Accepted 9 April 2007

In this report, we describe an optimized method for generation of ephA8 BAC transgenic mice expressing the lac $Z$ reporter gene under $e p h A 8$ regulatory sequences. First, we constructed a targeting vector that carries a 1.2 kb eph A8 DNA upstream of its first exon, a lacZ expression cassette, a kanamycin cassette, and a $0.7 \mathrm{~kb} e p h A 8$ DNA downstream of its first exon. Second, the targeting vector was electroporated into cells containing the eph $A 8 \mathrm{BAC}$ and pKOBEGA, in which recombinases induce a homologous recombination between the eph $A 8$ BAC DNA and the targeting vector. Third, the FLP plasmid expressing the Flipase was electroporated into these bacteria to eliminate a kanamycin cassette from the recombinant BAC DNA. The appropriate structures of the modified eph $A 8$ BAC DNA were confirmed by Southern analysis. Finally, BAC transgenic mouse embryos were generated by pronuclear injection of the recombinant BAC DNA. Whole mount X-gal staining revealed that the lac $Z$ reporter expression is restricted to the anterior region of the developing midbrain in each transgenic embryo. These results indicate that the eph $A 8$ BAC DNA contains most, if not all, regulatory sequences to direct temporal and spatial expression of the lacZ gene in vivo.

Keywords: BAC, EphA8, Transgenics

\section{Introduction}

BACs (bacterial artificial chromosome) are large genomic DNA fragments, generally $100-300 \mathrm{~kb}$ in size, that are cloned into bacterial plasmids which can be propagated in large quantities in E. coli cultures (Shizuya et al., 1992; Kim et al., 1996; Tao and Zhang, 1998; Frengen et al., 1999). Since their

* To whom correspondence should be addressed.

Tel: 82-2-710-9330; Fax: 82-2-715-9331

E-mail: scpark@sookmyung.ac.kr genomic fragments are large and contain most regulatory sequences of a gene, BACs are most useful for inducing stable and tissue-specific expression of heterologous genes in vivo in BAC-transgenic mice.

Conventional transgenic techniques using plasmids or phage vectors with relatively short inserts $(<50 \mathrm{~kb})$ have had many limitations because introns and essential regulatory elements are easily omitted in these constructs. In addition, the positioneffect often influences foreign gene expression, depending on the chromosomal integration site (Abe et al., 2004). Due to these drawbacks, transgene expression often fails to match the expression patterns of the corresponding endogenous gene. These drawbacks can be overcome by BAC technology since large fragments of genomic DNA in BAC have a high probability of containing most regulatory elements and locus control regions. Currently, BAC-transgenic technology is ideally suited to analyzing gene expression in vivo, for example, for a large-scale project to create an atlas of CNS gene expression (Joyner et al., 2003). In addition, BAC technology represents a very powerful approach for spatial and temporal control of recombinase expression, which is essential for conditional gene knock-out technology.

BAC-transgenic technology requires modification of BAC DNA with a heterologous gene using a bacterial homologous recombination system. Several methods have been reported for insertion of genes or deletion of DNA segments in BACs using a bacterial homologous recombination system. In general, these methods can be classified into two categories, depending on whether RecA or the lambda recombination system is used. The first method is to use a shuttle vector carrying the gene of interest flanked by relatively short $(<1 \mathrm{~kb})$ homologous genomic fragments and the recombinase RecA, which directs homologous recombination between the shuttle vector and the BAC DNA in bacteria (Yang et al., 1997; Gong et al., 2002). The second method is to use the lambda recombination system, in which exo, bet, and gam are inducibly expressed from a plasmid (Muyrers et al., 1999; Datsenko and Wanner, 2000; Yu et al., 2000; Zhang et al., 2000). In this system, a linear DNA fragment carrying the 
gene modification flanked by very short genomic segments is introduced into BAC-containing bacteria, in which homologous recombination is directed by inducible lambda phage recombinases.

In this report, we established a $\mathrm{BAC}$ recombination technique, which is based on a lambda recombination system. Our approach allowed for reliable generation of ephA8 BAC transgenic mice, in which the expression pattern of the $l a c Z$ reporter gene correlated well with that of the endogenous ephA8 gene. This method should expedite the analysis of various ephA8 regulatory elements and facilitate tissuespecific expression of heterologous genes in vivo for gene function study.

\section{Materials and Methods}

Construction of targeting vector. Homology arms A and B flanking mouse ephA8 exon 1 were synthesized by PCR using the following primer sets: 5'-CATCTAGCTGGGGGACCTAGCGT-3' (forward primer for A arm), 5'-TGGCGCGCTCCTGCCTCTCCC GC-3' (reverse primer for A arm), 5'-CGCCTGTCCCCCGCTCTC TGGGT-3' (forward primer for B arm) and 5'-GAAGGGACCACC TGGCTTTGATT-3' (reverse primer for B arm). The targeting vector was constructed on the backbone of the pGEM $11 \mathrm{Z}$ vector (Promega) as follows. First, pGEM11Z was digested with ApaI and then a homologous B arm inserted into this site. Second, the homologous arm A and lacZ containing the SV40 polyadenylation site were cloned into the $X h o I$ site before the B arm in pGEM11Z, and then a FRT-Kana-FRT cassette was inserted into the SpeI site present in between the lacZ-pA and B arm. This targeting vector was digested with $N$ sil/Sfil followed by purification of the insert on a $0.8 \%$ low-melting agarose gel.

BAC modification by homologous recombination. For the first homologous recombination, BAC host cells were streaked on an agar plate supplemented with chloramphenicol and incubated overnight at $37^{\circ} \mathrm{C} .5 \mathrm{ml}$ of Luria broth (LB) supplemented with chloramphenicol was inoculated with a single colony and grown at $37^{\circ} \mathrm{C}$ overnight with shaking. The next day, $1 \mathrm{ml}$ of the overnight culture $\left(\mathrm{OD}_{600}=1.2\right)$ was transferred to $10 \mathrm{ml}$ of $\mathrm{LB}$ and grown to $\mathrm{OD}_{600}=0.7-0.8$. The cells were then collected by centrifugation at 4,000 r.p.m. for $1 \mathrm{~min}$ in a $1.5 \mathrm{ml}$ microtube at $4^{\circ} \mathrm{C}$. The cell pellets were then resuspended in $888 \mu \mathrm{l}$ of ice-cold water. Cells were transferred to a $1.5 \mathrm{ml}$ microtube on ice and centrifuged using a cooling centrifuge for $1 \mathrm{~min}$ at $4^{\circ} \mathrm{C}$. The tubes were placed on ice and the supernatant fluids aspirated. This process was then repeated two additional times. Finally, the cell pellet was resuspended in 50 $\mu \mathrm{l}$ of ice-cold water and transferred to a pre-cooled electroporation cuvette (BIO-RAD). Next, $10 \mathrm{ng}$ of pKOBEGA plasmids were added and mixed (Depaepe et al., 2005). Electroporation was performed using a BIO-RAD electroporator and $1 \mathrm{ml}$ of LB added to the cuvette, which was incubated at $30^{\circ} \mathrm{C}$ for $1 \mathrm{~h}$. Cells were spread on plates containing chloramphenicol and ampicillin. The next day, a single chloramphenicol and ampicillin-resistant colony was selected and inoculated with $5 \mathrm{ml}$ of LB supplemented with chloramphenicol and ampicillin, and grown to $\mathrm{OD}_{600}=1.2 .1 \mathrm{ml}$ of the overnight culture $\left(\mathrm{OD}_{600}=1.2\right)$ was then transferred to $10 \mathrm{ml}$ of $\mathrm{LB}$ and grown to $\mathrm{OD}_{600}=0.05-0.1$. Next, $10 \% \mathrm{~L}(+)$ arabinose (Sigma A-3256) in D.W. was added to the culture to a final concentration of $0.2 \%$ and shaken at $30^{\circ} \mathrm{C}$ for another hour. Cells were then collected, and the cell pellets washed as described above. Next, $1 \mu \mathrm{g}$ of linear targeting vector was eletroporated into $50 \mu \mathrm{l}$ of competent cells. Then $1.0 \mathrm{ml}$ of LB was added to the electroporation cuvette and 10-100 $\mu \mathrm{l}$ of the cells subsequently plated onto a plate containing kanamycin and chloramphenicol and incubated at $37^{\circ} \mathrm{C}$ overnight.

For the second recombination, the first recombinant BAC clones were identified and inoculated with $5 \mathrm{ml}$ of LB supplemented with chloramphenicol and kanamycin, and grown to $\mathrm{OD}_{600}=1.2 .1 \mathrm{ml}$ of the overnight culture $\left(\mathrm{OD}_{600}=1.2\right)$ was then transferred to $10 \mathrm{ml}$ of $\mathrm{LB}$ and grown to $\mathrm{OD}_{600}=0.7-0.8$. Cells were collected and the pellets washed as described above. Next, $10 \mathrm{ng}$ of FLP plasmid (Gene Bridges) was eletroporated into $50 \mu \mathrm{l}$ of competent cells. Then $1.0 \mathrm{ml}$ of LB was added to the electroporation cuvette and 10 $-100 \mu \mathrm{l}$ of the cells subsequently plated onto a plate containing tetracycline, kanamycin and chloramphenicol and incubated at $30^{\circ} \mathrm{C}$ overnight. $5 \mathrm{ml}$ of LB supplemented with chloramphenicol was inoculated with a single colony and incubated at $30^{\circ} \mathrm{C}$ with shaking. $1 \mathrm{ml}$ of the overnight culture $\left(\mathrm{OD}_{600}=1.2\right)$ was transferred to $20 \mathrm{ml}$ of $\mathrm{LB}\left(\mathrm{OD}_{600}=0.05-0.1\right)$ and incubated for $2 \mathrm{~h}$ with shaking $\left(\mathrm{OD}_{600}=0.5\right)$. Next, $10 \mathrm{ml}$ of the cells were transferred to a new flask and shaken in a $42^{\circ} \mathrm{C}$ water bath for $15 \mathrm{~min}$. The cells were put into wet ice and the flask shaken to make sure that the temperature dropped as rapidly as possible, then the flask was left in wet ice for another $5 \mathrm{~min}$. 10-100 $\mu$ of cells were subsequently spread onto a plate containing chloramphenicol and incubated at $37^{\circ} \mathrm{C}$ overnight. We used the following antibiotic concentrations in our experiments: chloramphenicol, $12.5 \mu \mathrm{g} / \mathrm{ml}$; ampicillin, $50 \mu \mathrm{g} /$ $\mathrm{ml}$; kanamycin, $20 \mu \mathrm{g} / \mathrm{ml}$; tetracycline, $15 \mu \mathrm{g} / \mathrm{ml}$.

Generation and analysis of BAC transgenic mice. Modified BAC DNA was prepared using the large-construct kit (Qiagen). The quality and concentration of the DNA was checked on a gel and the BAC DNA diluted to $10 \mathrm{ng} / \mu \mathrm{l}$ in injection buffer $(10 \mathrm{mM}$ Tris- $\mathrm{HCl} \mathrm{pH}$ 7.5, 0.1 mM EDTA pH 8.0 and $100 \mathrm{mM} \mathrm{NaCl})$. An aliquot of DNA was mixed with the same amount of $2 \mathrm{X}$ polyamine (50:50) $48 \mathrm{~h}$ to 1 week before the injection. The BAC DNA ( $5 \mathrm{ng} /$ $\mu \mathrm{l})$ was injected into 200 pronuclei of fertilized oocytes of C57BL/ 6 mice as described previously (Gong et al., 2003; Koo et al., 2003; Sparwasser et al., 2003). BAC transgenic mice and embryos were identified by PCR using the primers 5'-GCGGGAGAGGCAGGA GCGCGCCA-3' and 5'-CGGAAACCAGGCAAAGCGCCAT-3'.

Whole mount X-gal staining and Southern blot analysis. Embryos to be stained were dissected in phosphate buffered saline (PBS), fixed in $0.2 \%$ glutaraldehyde, and washed three times in washing buffer. These embryos were placed in $\beta$-galactosidase staining solution for $1-5 \mathrm{~h}$ at $37^{\circ} \mathrm{C}$, and post-fixed in $4 \%$ PFA as described previously (Joyner et al., 1993; Park et al., 1997; Koo et al., 2003). Southern blot was performed as described previously (Sambrook et al., 2001). 


\section{Results}

Modification of eph $A 8$ BAC DNA with a targeting vector in bacterial system. The EphA8 gene contains 17 exons and is about $28 \mathrm{~kb}$ in length (Fig. 1A and B). For analysis of the ephA8 gene expression, a BAC clone, RP23-357K18, was selected for modification using the bacterial homologous recombination method. This BAC DNA contains the ephA8 gene approximately in the center of its genomic insert, and is therefore likely to contain most of the regulatory elements and locus control regions (Fig. 1A). This BAC clone is about 287 $\mathrm{kb}$ in length and contains other genes, including zbtb40, Clqa, $C 1 q b, C 11 q c$, and ephB2.

For modification of the ephA8 BAC DNA, we first transformed

(A)

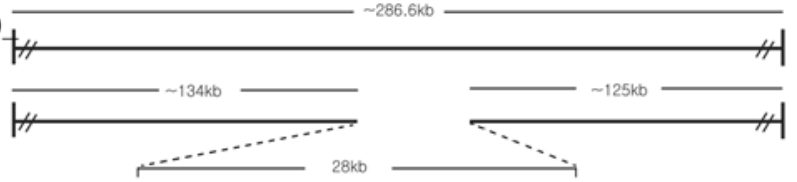

(B)

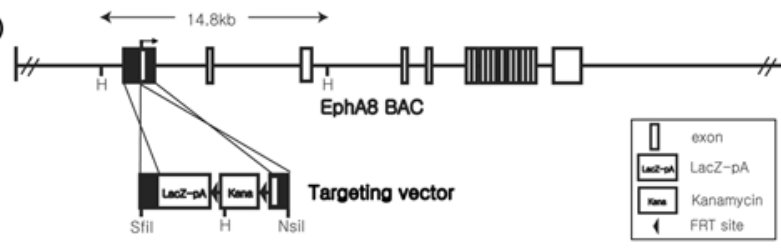

First Homologous Recombination

(C)

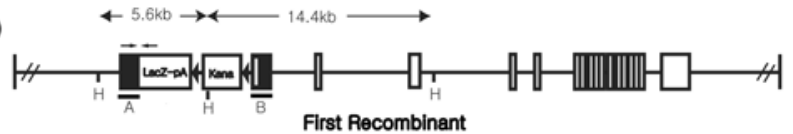

(D)

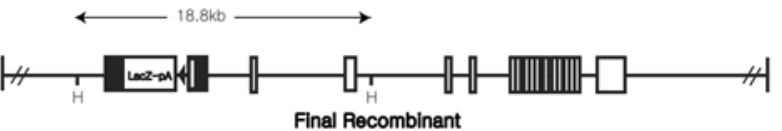

Fig. 1. Strategy for the ephA8 BAC modification. (A) Location and size of the ephA8 gene locus on the RP23-357K18 BAC clone. Note that the ephA8 gene is approximately $28 \mathrm{~kb}$ long as represented by a thin line. (B) The first homologous recombination between the linearized targeting vector and the BAC DNA containing the ephA8 gene. Note that the black boxes indicate the homologous genomic DNAs present in both the targeting vector and ephA8 BAC. H, HindIII. (C) The genomic structure of the modified ephA8 BAC DNA in which the targeting vector was integrated through the first homologous recombination. A and $\mathrm{B}$ represent the left and right homologous arms, respectively. (D) The genomic structure of the modified ephA8 BAC DNA in which the FRT-Kana-FRT cassette was selectively removed by Flipase recombinase. This modified ephA $8 \mathrm{BAC}$ is identical with the original ephA8 BAC, RP23-357K18, except that it contains the lac $Z$ gene in-framed with the first exon in ephA8.
pKOBEGA plasmid carrying an inducible lambda phage recombinase system into the bacteria containing the ephA8 BAC DNA, and the transformants were selected at $30^{\circ} \mathrm{C}$ in the presence of chloramphenicol and ampicilin, as previously described (Depaepe et al., 2005). Recombinases were then induced by incubating these bacteria in arabinose-containing medium. Next, an ephA8 targeting vector containing a $1.2 \mathrm{~kb}$ DNA upstream of the first exon, a $3.5 \mathrm{~kb}$ lacZ-pA cassette, a $2.3 \mathrm{~kb}$ kanamycin resistance gene flanked by FRT sites, and a $0.7 \mathrm{~kb}$ DNA downstream of the first exon was constructed (Fig. 1B). This vector was electroporated into the bacteria containing the ephA8 BAC DNA and pKOBEGA. In this system, the arabinose-induced recombinases mediate a homologous recombination between a targeting vector and the ephA8 BAC DNA, and the recombinant BAC clones were further selected by incubation at $37^{\circ} \mathrm{C}$ in the presence of chloroamphenicol and kanamycin. The integrity and structure of this modified BAC DNA containing the targeting vector was assessed by Southern blot (Fig. 2). As expected, a $14.8 \mathrm{~kb}$ fragment of the HindIII-digested wild-type BAC DNA was hybridized by probe $\mathrm{A}$ and $\mathrm{B}$ (Fig. $2 \mathrm{~A}$ and $\mathrm{B}$, lane 1). When DNAs from the first BAC recombinant clones were digested with HindIII, the $5.6 \mathrm{~kb}$ fragment was hybridized with probe A (Fig. 2A, lanes 2-3) or lacZ (Fig. 2C, lanes 2-3), and a 14.4 $\mathrm{kb}$ fragment was hybridized with probe $\mathrm{B}$ (Fig. 2B, lanes 2-3), indicating that these clones carry cointegrates that occurred through the region of homology. Finally, FLP plasmid was electroporated into cells containing the first recombinant $\mathrm{BAC}$ DNA, and the transformants were selected at $30^{\circ} \mathrm{C}$ in the presence of choloramphenicol, kanamycin and tetracycline.

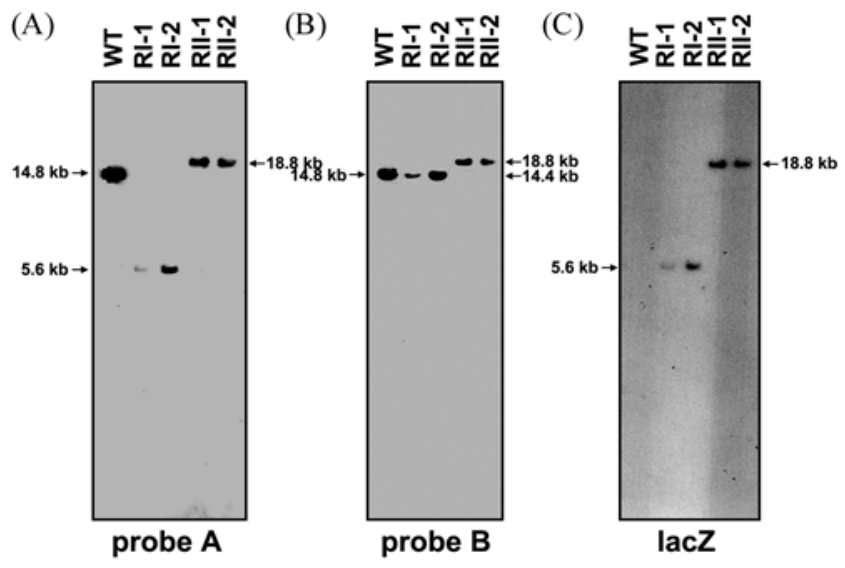

Fig. 2. Southern blot analyses of the modified BAC DNAs. The BAC DNAs from the indicated BAC clones were digested with HindIII and then analyzed by Southern blot using the indicated probes. WT denotes the original ephA8 BAC clone, RP23357K18. RI-1 and RI-2 represent two independent recombinant $\mathrm{BAC}$ clones, which were generated by the first homologous recombination. Likewise, RII-1 and RII-2 indicate two independent BAC clones induced by Flipase. The arrows represent the HindIII-digested BAC DNA fragments hybridized with the indicated probes. 
Flipase was then induced by incubating at $42^{\circ} \mathrm{C}$ to eliminate a kanamycin cassette between two FRT sites, and the final recombinant $\mathrm{BAC}$ clones were cultured at $37^{\circ} \mathrm{C}$ in the presence of chloramphenicol. An appropriate structure of the final BAC DNAs was investigated by Southern blot, revealing that the same DNA fragment, which corresponded to appropriately $18.8 \mathrm{~kb}$, was hybridized by probe $\mathrm{A}, \mathrm{B}$, and lacZ, respectively (Fig. 2A-C, lanes 4-5). Taken together, these results indicate that an ephA8 BAC clone, RP23$357 \mathrm{~K} 18$, was appropriately modified to contain a lacZ expression cassette inserted into the first exon of the ephA8 gene through homologous recombination.

\section{Production of ephA8 BAC transgenic mice and in vivo} reporter expression analysis. To generate ephA8 $\mathrm{BAC}$ transgenic mice, we used BAC DNAs of $5 \mathrm{ng} / \mu \mathrm{l}$ concentration for pronuclear injection into fertilized C57BL/6 mouse zygotes (Gong et al., 2003; Koo et al., 2003; Sparwasser et al., 2003). As shown in Fig. 3, seven embryos at embryonic day (E) 10.5 were obtained from a foster mother and subjected to PCR analysis to determine whether they contained the modified BAC DNA. One of these revealed an expected PCR product (lane 3), confirming that the ephA8 BAC DNA was stably integrated into the mouse genome. We established at least three different transgenic lines after several rounds of microinjections. Two of these transgenic lines were crossed to generate transgenic embryos in order to investigate the temporal and spatial expression of lac $Z$ in vivo. As shown in Fig. 4, lacZ expression patterns of ephA8 BAC transgenic embryos derived from two different lines (panels C-F) were compared with those of the ephA $8^{\text {lac } / \text { lac }}$ embryo (panels A and B) using whole-mount X-gal staining (Park et al., 1997). The most prominent expression was observed in the anterior region of dorsal mesencephalon for both the ephA8 BAC embryo and eph $A 8^{\text {lacZlacz }}$ embryo. Interestingly, lacZ expression was more laterally extended in the ephA8 BAC transgenic embryo (panel D), possibly due to over-expression of lac $Z$ in each transgenic embryo. In addition, ectopic expression was also observed in many other tissues of one particular ephA 8 BAC transgenic embryo shown in Fig. $4 \mathrm{C}$ and D, suggesting

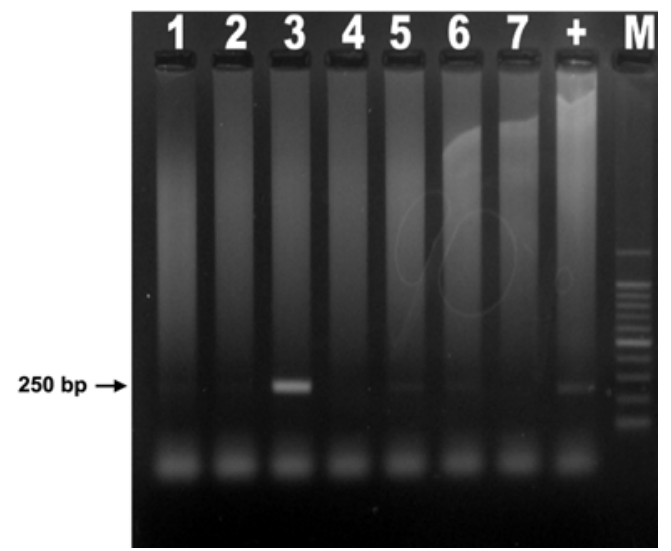

Fig. 3. Generation of the ephA8 BAC transgenic line. PCR analysis was performed using tail genomic DNAs derived from seven littermates. One of these littermates showed the expected $250 \mathrm{bp}$ PCR product, suggesting that this line is a potential transgenic line. Note that only $0.1 \mathrm{ng}$ of BAC DNA was used as a positive control for PCR analysis. + , a positive control DNA derived from RII-1 BAC clone; M, a 100 bp marker.

that this ectopic expression pattern is likely due to the integration site of the BAC DNA. Nevertheless, these results strongly indicate that the reporter expression of the ephA8 BAC transgenic embryo is very similar to that of the ephA $8^{\text {lacZ/lacz }}$ embryo.

\section{Discussion}

In this report, ephA8 BAC DNA was modified to contain a lacZ reporter downstream of the ephA8 promoter through a bacterial homologous recombination system. This BAC DNA was stably integrated into the mouse genome and shown to express the reporter in the developing midbrain as the endogenous ephA8 gene, indicating that BAC technology represents a powerful approach to study of the ephA8 gene regulation and function in vivo.

To date, several methods have been described to use BAC

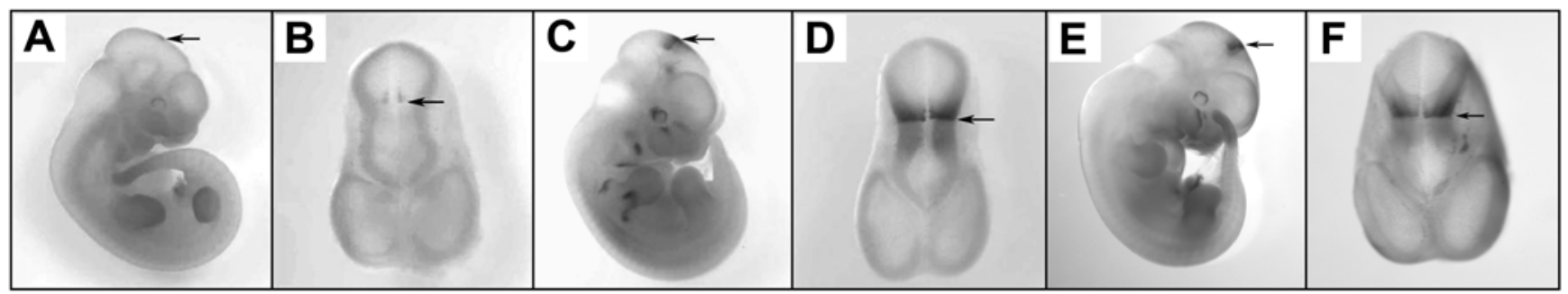

Fig. 4. Analysis of lacZ expression for the ephA8 BAC transgenic embryo. EphA8 BAC transgenic and ephA $8^{\text {lacZlacZ }}$ embryos at embryonic day (E) 10.5 were analyzed for LacZ activity by whole mount X-gal staining. (A, B) Lateral and dorsal view of the ephA $8^{\text {lacZlacz }}$ embryo, respectively. $(\mathrm{C}, \mathrm{D})$ Lateral and dorsal view of the ephA8 BAC transgenic embryo, respectively. (E, F) Lateral and dorsal view of the ephA 8 BAC transgenic embryo derived from the different transgenic line, respectively. The black arrows indicate a boundary between diencephalon and mesencephalon. 
DNA in introducing modification and transgenesis (Gong et al., 2002; Abe et al., 2004; Depaepe et al., 2005). The Heinz group reported a method in which BAC-containing bacteria are transformed with a shuttle vector carrying the gene modification flanked by BAC homologous DNA fragments and RecA bacterial recombinase (Gong et al., 2002). Although this method has been reported as a comprehensive and highly optimized method, we have encountered some difficulties, including subcloning of DNA fragments into the shuttle vector in pir 2 competent cells, especially when manipulating large fragments. In addition, we found that the RecAmediated recombination system did not work for certain genomic DNA fragments. The second method uses homologous recombination via an inducible lambda phage recombinase system encoded on a separate vector or in modified bacteria (Muyrers et al., 1999). In this system, the linear modification cassette can be generated by PCR without any cloning steps. However, in our study, PCR generated mutations on the amplified DNAs, especially in the FRT site, caused a serious problem for elimination of the kanamycin cassette through Flipase-mediated recombination. The method we describe here is highly optimized for generation of BACtransgenic mice, which is modified from the approach developed by the Vanderhaeghen group (Depaepe et al., 2005). We have used a conventional subcloning method to generate a targeting vector, which was further induced to recombine with BAC DNA using a lambda phage recombinase system encoded on a pKOBEGA plasmid. Then, the kanamycin cassette was eliminated using a flipase recombinase system encoded on a FLP plasmid (Buchholz et al., 1996). Our method was very reliable and efficient since we used a specific bacterial recombination system and antibiotics selection to allow the specific recombinants to grow, although our approach may potentially be slow due to the many steps required for subcloning. We have not encountered any problems using the lambda recombination system that caused BAC instability due to its high recombination efficiency.

There is a high demand for the use of recombinases and inducible promoters for spatial and temporal control of gene expression in vivo in the study of gene function. BAC DNAs have a high probability of harboring most regulatory elements in the gene of interest as well as boundary elements of chromatin domains or locus control regions that insulate from regulatory influence by neighboring genes. This advantage makes BAC-transgenic mice ideal for analysis of gene expression and function in vivo (Depaepe et al, 2005; Jeong et al., 2006; Kim et al., 2006). Our BAC technology described here offers many potential uses including in vivo expression of dominant negative mutants and analysis of $c i s$-acting regulatory elements.

Acknowledgments We thank Jean-Marc Ghigo for providing pKOBEGA plasmid. This work was supported by Sookmyung Women's University in 2006.

\section{References}

Abe, K., Hazama, M., Katoh, H., Yamamura, K. and Suzuki, M. (2004) Establishment of an efficient BAC transgenesis protocol and its application to functional characterization of the mouse Brachyury locus. Exp. Anim. 53, 311-320.

Buchholz, F., Angrand, P. O. and Stewart, A. F. (1996) A simple assay to determine the functionality of Cre or FLP recombination targets in genomic manipulation constructs. Nucleic Acids Res. 24, 3118-3119.

Chaveroche, M. K., Ghigo, J. M. and d'Enfert, C. (2000) A rapid method for efficient gene replacement in the filamentous fungus Aspergillus nidulans. Nucleic Acids Res. 28, 97.

Copeland, N. G., Jenkins, N. A. and Court, D. L. (2001) Recombineering: a powerful new tool for mouse functional genomics. Nat. Rev. Genet. 2, 769-779.

Court, D. L., Sawitzke, J. A. and Thomason, L. C. (2002) Genetic engineering using homologous recombination. Annu. Rev. Genet. 36, 361-388.

Datsenko, K. A. and Wanner, B. L. (2000) One-step inactivation of chromosomal genes in Escherichia coli K-12 using PCR products. Proc. Natl. Acad. Sci. USA 97, 6640-6645.

Depaepe, V., Suarez-Gonzalez, N., Dufour, A., Passante, L., Gorski, J. A., Jones, K. R., Ledent, C. and Vanderhaeghen, P. (2005) Ephrin signalling controls brain size by regulating apoptosis of neural progenitors. Nature 435, 1244-1250.

Festenstein, R., Tolaini, M., Corbella, P., Mamalaki, C., Parrington, J., Fox, M., Miliou, A., Jones, M. and Kioussis, D. (1996) Locus control region function and heterochromatininduced position effect variegation. Science 271, 1123-1125.

Frengen, E., Weichenhan, D., Zhao, B., Osoegawa, K., van Geel, M. and de Jong, P. J. (1999) A modular, positive selection bacterial artificial chromosome vector with multiple cloning sites. Genomics 58, 250-253.

Gong, S., Yang, X. W., Li, C. and Heintz, N. (2002) Highly efficient modification of bacterial artificial chromosomes (BACs) using novel shuttle vectors containing the R6Kgamma origin of replication. Genome Res. 12, 1992-1998.

Gong, S., Zheng, C., Doughty, M. L., Losos, K., Didkovsky, N., Schambra, U. B., Nowak, N. J. and Heintz, N. (2001) BAC to the future: the use of bac transgenic mice for neuroscience research. Nat. Rev. Neurosci. 2, 861-870.

Jeong, Y., El-Jaick, K., Roessler, E., Muenke, M. and Epstein, D. J. (2006) A functional screen for sonic hedgehog regulatory elements across a $1 \mathrm{Mb}$ interval identifies long-range ventral forebrain enhancers. Development 133, 761-772.

Joyner, A., Leblanc, G., Hatten, M. E. and Heintz, N. (2003) A gene expression atlas of the central nervous system based on bacterial artificial chromosomes. Nature 425, 917-925.

Joyner, A. L. (1993) Gene targeting: a practical approach. Oxford University Press, Oxford, New York, USA.

Kim, J. and Lauderdale, J. D. (2006) Analysis of Pax6 expression using a BAC transgene reveals the presence of a paired-less isoform of Pax6 in the eye and olfactory bulb. Dev. Biol. 292, 486-505.

Kim, U. J., Birren, B. W., Slepak, T., Mancino, V., Boysen, C., Kang, H. L., Simon, M. I. and Shizuya, H. (1996) Construction and characterization of a human bacterial artificial chromosome library. Genomics 34, 213-218.

Koo, J., Shim, S., Gu, C., Yoo, O. and Park, S. (2003) 
Identification of an enhancer region in the mouse ephA8 locus directing expression to the anterior region of the dorsal mesencephalon. Dev. Dyn. 226, 596-603.

Lee, E. C., Yu, D., Martinez de Velasco, J., Tessarollo, L., Swing, D. A., Court, D. L., Jenkins, N. A. and Copeland, N. G. (2001) A highly efficient Escherichia coli-based chromosome engineering system adapted for recombinogenic targeting and subcloning of BAC DNA. Genomics 73, 56-65.

Liu, P., Jenkins, N. A. and Copeland, N. G. (2003) A highly efficient recombineering-based method for generating conditional knockout mutations. Genome Res. 13, 476-484.

Metcalf, W.W., Jiang, W., Daniels, L. L., Kim, S. K., Haldimann, A. and Wanner, B. L. (1996) Conditionally replicative and conjugative plasmids carrying lacZ alpha for cloning, mutagenesis, and allele replacement in bacteria. Plasmid 35, 113.

Muyrers, J. P., Zhang, Y., Testa, G. and Stewart, A. F. (1999) Rapid modification of bacterial artificial chromosomes by ETrecombination. Nucleic Acids Res. 27, 1555-1557.

Orford, M., Nefedov, M., Vadolas, J., Zaibak, F., Williamson, R. and Ioannou, P. A. (2000) Engineering EGFP reporter constructs into a $200 \mathrm{~kb}$ human beta-globin BAC clone using GET Recombination. Nucleic Acids Res. 28, 84.

Park, S., Frisen, J. and Barbacid, M. (1997) Aberrant axonal projections in mice lacking EphA8 (Eek) tyrosine protein kinase receptors. $E M B O J .16,3106-3114$.

Sambrook, J. and Russell, D. W. (2001) Molecular cloning: A laboratory manual, 2nd edition. Cold Spring Harbor Laboratory Press, Cold Spring Harbor, New York, USA.

Shizuya, H., Birren, B., Kim, U. J., Mancino, V., Slepak, T., Tachiiri, Y. and Simon, M. (1992) Cloning and stable maintenance of 300-kilobase-pair fragments of human DNA in Escherichia coli using an F-factor-based vector. Proc. Natl. Acad. Sci. USA 89, 8794-8797.

Sparwasser, T., Gong, S., Li, J. Y. and Eberl, G. (2004) General method for the modification of different BAC types and the rapid generation of BAC transgenic mice. Genesis 38, 39-50.

Swaminathan, S., Ellis, H. M., Waters, L. S., Yu, D., Lee, E. C., Court, D. L. and Sharan, S. K. (2001) Rapid engineering of bacterial artificial chromosomes using oligonucleotides. Genesis 29, 14-21.

Tao, Q. and Zhang, H. B. (1998) Cloning and stable maintenance of DNA fragments over $300 \mathrm{~kb}$ in Escherichia coli with conventional plasmid-based vectors. Nucleic Acids Res. 26, 4901-4909.

Yang, X. W., Model, P. and Heintz, N. (1997) Homologous recombination based modification in Escherichia coli and germline transmission in transgenic mice of a bacterial artificial chromosome. Nat. Biotechnol. 15, 859-865.

Yu, D., Ellis, H. M., Lee, E. C., Jenkins, N. A., Copeland, N. G. and Court, D. L. (2000) An efficient recombination system for chromosome engineering in Escherichia coli. Proc. Natl. Acad. Sci. USA 97, 5978-5983.

Zhang, P., Li, M. Z. and Elledge, S. J. (2002) Towards genetic genome projects: genomic library screening and gene-targeting vector construction in a single step. Nat. Genet. 30, 31-39.

Zhang, Y., Buchholz, F., Muyrers, J. P. and Stewart, A. F. (1998) A new logic for DNA engineering using recombination in Escherichia coli. Nat. Genet. 20, 123-128.

Zhang, Y., Muyrers, J. P., Testa, G. and Stewart, A. F. (2000) DNA cloning by homologous recombination in Escherichia coli. Nat. Biotechnol. 18, 1314-1317. 